\title{
High-Velocity Oxygen Fuel Thermal Spray of Fe-Based Amorphous Alloy: a Numerical and Experimental Study
}

\author{
L. AJDELSZTAJN, J. DANNENBERG, J. LOPEZ, N. YANG, J. FARMER, \\ and E.J. LAVERNIA
}

\begin{abstract}
The fabrication of dense coatings with appropriate properties using a high velocity oxygen fuel (HVOF) spray process requires an in-depth understanding of the complete gas flow field and particle behavior during the process. A computational fluid dynamics (CFD) model is implemented to investigate the gas flow behavior that occurs during the HVOF process and a simplified one-dimensional decoupled model of the in-flight thermal behavior of the amorphous Fe-based powder particles was developed and applied for three different spray conditions. The numerical results were used to rationalize the different coating microstructures described in the experimental results. Low porosity and amorphous coatings were produced using two different particle size distributions (16 to $25 \mu \mathrm{m}$ and 25 to $53 \mu \mathrm{m}$ ). The amorphous characteristics of the powder were retained in the coating due to melting and rapid solidification in the case of very fine powder or ligaments $(<16 \mu \mathrm{m})$ and to the fact that the crystallization temperature was not reached in the case of the large particles (16 to $53 \mu \mathrm{m})$.
\end{abstract}

DOI: $10.1007 / \mathrm{s} 11661-009-9900-7$

(C) The Author(s) 2009. This article is published with open access at Springerlink.com

\section{INTRODUCTION}

THERE has been increasing interest in producing Fe-based amorphous alloy coatings on crystalline substrates due to their fundamental scientific importance and attractive combinations of engineering properties: improved strength and hardness, greater wear resistance, and corrosion resistance. ${ }^{[1-3]}$ In the past decade, a series of new bulk amorphous alloys with multicomponent chemistry and high glass-forming ability have been developed in $\mathrm{Zr}-, \mathrm{Mg}-$, La-, Pd-, Ti-, and Fe-based systems ${ }^{[4-11]}$ with various rapid solidification techniques. The discovery of bulk amorphous alloys has opened up the opportunity for the synthesis of thick amorphous alloy coatings via thermal spray processes.

Thermal spray coatings may involve high cooling rates due to the small size of droplets impinging onto the cold substrate, forming a splat, quenching, and bonding to the cold substrate surface with a large contact area. The microstructure evolution of the sprayed coating is influenced by both momentum and thermal transport between

L. AJDELSZTAJN, formerly Research Scientist with the Department of Chemical Engineering and Materials Science, University of California, is Reserach Scientist with GE Global Research, Niskayuna, NY, 12309. Contact emil: ajdelsztajn@ge.com J. DANNENBERG, Senior Engineer, and E.J. LAVERNIA, Dean School of Engineering, are with the Department of Chemical Engineering and Materials Science, University of California, Davis, CA 95616. J. LOPEZ, Associate Professor, is with the Department de Ingeniería de Materiales y Fabricación, ETSII, Universidad Politécnica de Cartagena, E-30202 Cartagena, Spain. N. YANG, Distinguished Member of Technical Staff, is with the Sandia National Laboratory, Livermore, CA 94551. J. FARMER, Associate Program Leader, Nuclear Science and Systems Engineering Program, is with the Lawrence Livermore National Laboratory, Livermore, CA 94550.

Manuscript submitted March 13, 2007.

Article published online July 21, 2009 the flame gas and the powder particles during flight. With decreasing powder particle size, the cooling rate increases, and formation of intermetallic compounds can be suppressed in thermal spray coatings, forming an amorphous structure. ${ }^{[12]}$ High velocity oxygen fuel (HVOF) thermal spray is a widely used thermal spraying technology in both research and industry, due to its flexibility and the superior quality coatings that it generates. High particle kinetic energy is available in HVOF processing, resulting in increased thickness, higher bond strength, and lower porosity. The HVOF thermal spraying technique was first developed in the late 1970s and early 1980s. Since then, it has been widely used to produce protective coatings, typically, $100-$ to $800-\mu \mathrm{m}$ thick, on the surfaces of engineering components. ${ }^{[1-3]}$ The materials sprayed include metallic alloys, ceramics, and polymers. In the HVOF process, oxygen and a fuel gas are mixed and reacted in a combustion gun at high pressures in order to produce a gas jet with high temperature and high speed. ${ }^{[2,3]}$ At the same time, powder particles, normally in the range size of 15 to $53 \mu \mathrm{m}$, are delivered into the gun system, where they are heated and accelerated toward the exit of the supersonic nozzle. The particles are either partially or fully melted due to heat transfer that occurs in the flight toward the substrate. On arrival at the substrate, particles are ideally softened and easily deformable and, upon impact, they adhere to the substrate and to each other. The HVOF gun scans across the substrate to build up the required coating thickness in a number of passes.

The properties of a thermally sprayed coating are strongly affected by the microstructure of the droplets and the phases formed during flight. These, in turn, will be determined by the process parameters, such as total gas flow rate, fuel-to-oxygen ratio, and standoff distance between gun and substrate. The gas flow behavior governs the thermal behavior of particles and the 


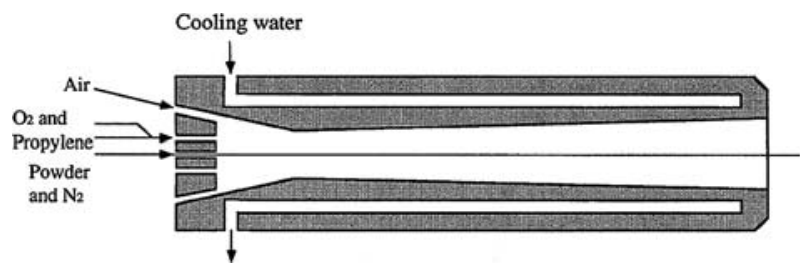

Fig. 1-Geometry of the convergent-divergent Laval nozzle.

subsequent mechanical properties of coatings. Several previous numerical computational fluid dynamics (CFD) simulations have investigated gas and particle flows in HVOF thermal spray guns. ${ }^{[13-21]}$ Whereas a similar numerical analysis is used in the present study, our aim is to provide insight into the behavior of amorphous $\mathrm{Fe}$, which has heretofore never being studied. Accordingly, in this study, we seek to understand the influence of spray conditions on particle velocity and temperature during flight, and, ultimately, how they are related to the coating microstructure.

In the current work, a CFD model was developed for an HVOF gun design similar to the Sulzer-Metco Diamond Jet gun system (Sulzer Metco, Westbury, NY). A schematic representation of this gun is shown in Figure 1. Oxygen and propylene are injected into a watercooled convergent-divergent nozzle, through an annular array of fine orifices, where the chemical reaction takes place and the combustion products are accelerated down the nozzle exit. Powder particles are axially delivered into the combustion nozzle by a carrier gas (e.g., nitrogen). The mixture of particle and gas reaction products leaves the nozzle at a high temperature and velocity toward the substrate, which is typically placed 0.15 to $0.30 \mathrm{~m}$ from the nozzle exit. In this article, a simplified one-dimensional decoupled model of the in-flight thermal behavior of the amorphous Fe-based powder particles during the HVOF process will be briefly described and applied for three different spray conditions, and the numerical results will be used to explain the different coating microstructures described in the experimental results.

\section{CFD MODEL}

For the gun geometry shown in Figure 1, the flow is assumed to be axisymmetric and the computational domain consists of the gas inlets, the convergentdivergent nozzle, and an external region. In the present study, the fuel and oxygen inlet gas stream is modeled as an annular ring with the same total area as the equally spaced inlet orifices and is centered at the same radial location as the orifices. The carrier gas (e.g., nitrogen) enters the gun through the powder inlet orifice, although in the present analysis a solid particle flow was not included. Detailed computational assumptions and boundary conditions are described elsewhere. ${ }^{[13,14]}$

\section{A. Fluid Dynamics}

Because of the gun geometry, a two-dimensional, axisymmetric, steady-state simulation was performed in a commercially available software package, CFD-ACE. The basic equations solved by CFD-ACE are a series of viscous Navier-Stokes formulas, which include the conservation of mass, momentum, and energy in a compressible, turbulent, chemically reacted gas flow. ${ }^{[22]}$ Each gas mixture follows the Navier-Stokes formula. The mass fraction of each gas mixture is solved in the chemical combustion reactions described in Section B. The standard $k-\varepsilon$ turbulence model is applied along with the upwind and cell-centered control volume algorithm.

\section{B. Chemical Reactions}

In the present work, the propylene-plus-oxygen inlet stream is assumed to be completely mixed, and the combustion of propylene takes place in the combustion nozzle at an infinite reaction rate. Classically, the end products of propylene combustion are regarded as carbon dioxide and water:

$$
\mathrm{C}_{3} \mathrm{H}_{6}+4.5 \mathrm{O}_{2} \rightarrow 3 \mathrm{CO}_{2}+3 \mathrm{H}_{2} \mathrm{O}
$$

However, hydrocarbon combustion is a very complex process and may consist of a number of intermediate products. When the environment temperature is beyond $2000 \mathrm{~K}, \mathrm{CO}_{2}$ and $\mathrm{H}_{2} \mathrm{O}$ will dissociate into a number of different species, which is in the so-called equilibrium reaction. ${ }^{[15]}$ For a given oxygen-to-fuel ratio, e.g., $f$, the equation can be written as

$$
\begin{aligned}
\mathrm{C}_{3} \mathrm{H}_{6}+f \mathrm{O}_{2} \rightarrow & n_{1} \mathrm{CO}_{2}+n_{2} \mathrm{CO}+n_{3} \mathrm{H}+n_{4} \mathrm{H}_{2} \\
& +n_{5} \mathrm{H}_{2} \mathrm{O}+n_{6} \mathrm{O}+n_{7} \mathrm{OH}
\end{aligned}
$$

where $n_{i}$ represents the equilibrium number of moles of each of the intermediate products of the reaction. For a setup where temperature and pressure are fixed, these equilibrium constants, the $n_{i}$ values, can, in principle, be uniquely determined for a given value of oxygen-fuel ratio. A global, one-step chemistry rate equation for calculating equilibrium combustion reactions, taking into account dissociation, is suitable for representing the combustion process, as Oberkampf and Talpallikar suggested. ${ }^{[16]}$ In this article, the formula is given as

$$
\begin{aligned}
\mathrm{C}_{3} \mathrm{H}_{6}+3.552 \mathrm{O}_{2} \rightarrow & 1.036 \mathrm{CO}_{2}+1.964 \mathrm{CO} \\
& +0.44 \mathrm{H}+0.476 \mathrm{H}_{2}+1.937 \mathrm{H}_{2} \mathrm{O} \\
& +0.397 \mathrm{O}+0.734 \mathrm{OH}
\end{aligned}
$$

\section{PARTICLE THERMAL MODEL}

In this section, a simplified one-dimensional decoupled model of the in-flight thermal behavior of the powder particles during the HVOF process will be briefly described.

\section{A. Governing Equations}

We shall assume that the shape of the particles is perfectly spherical. Taking into account that the 
physical properties of the particle in the solid and liquid phases are independent of temperature and that no density change occurs during the solidification process, the nondimensional particle temperature $T^{\prime}$ as a function of time can be expressed in spherical coordinates as

$$
\begin{aligned}
& \frac{\partial T_{s}^{\prime}}{\partial t^{\prime}}=\frac{\alpha_{s}}{\alpha_{l}}\left(\frac{2}{x^{\prime}} \frac{\partial T_{s}^{\prime}}{\partial x^{\prime}}+\frac{\partial^{2} T_{s}^{\prime}}{\partial x^{\prime 2}}\right) \text { for } x^{\prime} \leq X_{I}^{\prime} \\
& \frac{\partial T_{l}^{\prime}}{\partial t^{\prime}}=\left(\frac{2}{x^{\prime}} \frac{\partial T_{l}^{\prime}}{\partial x^{\prime}}+\frac{\partial^{2} T_{l}^{\prime}}{\partial x^{\prime 2}}\right) \text { for } X_{I}^{\prime}<x^{\prime}<1
\end{aligned}
$$

where

$$
T^{\prime}=\frac{T-T_{0}}{T_{m}-T_{0}}, \quad t^{\prime}=\alpha_{l} \frac{t}{r_{p}^{2}}, \text { and } x^{\prime}=\frac{x}{r_{p}}
$$

where $T_{0}$ is the initial temperature of the particle; $T_{m}$ is the "normal" freezing temperature; $\alpha_{s, l}=k_{s, l} /\left(\rho_{s, l} c_{s, l}\right)$ is the thermal diffusivity with $\rho_{s, l}, c_{s, l}$, and $k_{s, l}$ the density, specific heat, and thermal conductivity of the particle, respectively; $x$ is the radial coordinate; and $r_{p}$ is the radius of the particle. Subscripts $s$ and $l$ denote, respectively, the solid and liquid phases. The nondimensional solid-liquid interface position $X_{I}^{\prime}$ is determined at each instant using the procedure described in the Section B. Figure 2 shows a schematic representation of the problem.

The initial and boundary conditions of the problem are given by

$$
\begin{gathered}
T_{s, l}^{\prime}\left(x^{\prime}, 0\right)=0 \\
\left.\frac{\partial T_{s, l}^{\prime}}{\partial x^{\prime}}\right|_{x^{\prime}=0}=0 \\
\left.\frac{\partial T_{s, l}^{\prime}}{\partial x^{\prime}}\right|_{x^{\prime}=0}=\operatorname{Bi}\left(T_{g}^{\prime}-T_{s, l}^{\prime}\right)
\end{gathered}
$$

where $T_{g}^{\prime}$ is the nondimensional surrounding gas temperature and $\mathrm{Bi}=h r_{p} / k_{s, l}$ is the Biot number. The heat-transfer coefficient $h$ was determined by the Ranz-Marshall semiempirical relation: ${ }^{[23]}$

$$
h=\frac{k_{g}}{2 r_{p}}\left(2+0.6 \operatorname{Re}^{1 / 2} \operatorname{Pr}^{1 / 3}\right)
$$

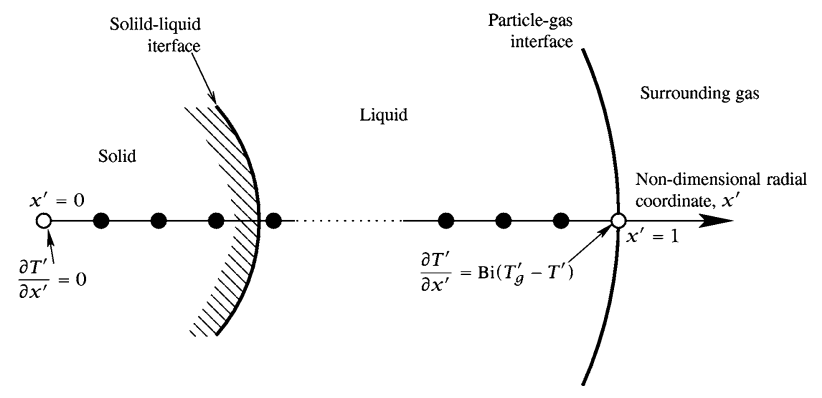

Fig. 2-Schematic representation of the problem. where $\operatorname{Re}=2 \rho_{g} r_{p}\left|\mathbf{v}_{p}-\mathbf{v}_{g}\right| / \mu_{g}$ and $\operatorname{Pr}=c_{p g} \mu_{g} / k_{g}$ are, respectively, the Reynolds and Prandtl numbers, $\rho_{g}$, $c_{p g}, \mu_{g}$, and $k_{g}$ being the density, specific heat, dynamic viscosity, and thermal conductivity of the gas, respectively; $\mathbf{v}_{g}$ the surrounding gas velocity; and $\mathbf{v}_{p}$ the particle velocity. The temperature and velocity of the surrounding gas are obtained from the numerical solution of the gas fluid equations, and, considering that the drag force plays a dominant role over other factors, ${ }^{[24]}$ the particle velocity $\mathbf{v}_{p}$ is obtained at each instant using the following expression:

$$
\frac{d \mathbf{v}_{p}}{d t}=\frac{3 c_{D} \rho_{g}}{8 r_{p} \rho_{p}}\left(\mathbf{v}_{g}-\mathbf{v}_{p}\right)\left|\mathbf{v}_{g}-\mathbf{v}_{p}\right|
$$

where $c_{D}$ is the drag coefficient, which depends on the Reynolds number and is obtained from the following empirical expression:

$$
\begin{aligned}
c_{D}= & \frac{24.0}{\operatorname{Re}}\left(1.0+0.1118 \operatorname{Re}^{0.6567}\right) \\
& +\frac{0.4305}{1.0+3305.0 / \operatorname{Re}}
\end{aligned}
$$

\section{B. Numerical Procedure}

Equations [4] and [5] are discretized using central differences for the spatial derivatives and a fully implicit time integration scheme, which allows large time-steps to be used. The boundary conditions given by Eqs. [7] and [8] are discretized using, respectively, second-order forward and backward finite difference approximations, and Eq. [10] is integrated over each time interval using a second-order Runge-Kutta method (for example, Press et al. ${ }^{[25]}$ ).

Equations [4] and [5] have been resolved separately for the solid and liquid phases, respectively. To this end, extrapolated temperature values on both sides of the solid-liquid interface are obtained in the following way. The signed distance $\phi$ to the interface is computed on both solid $\left(\phi_{s}>0\right)$ and liquid $\left(\phi_{l}<0\right)$ nodes close to the interface and the corresponding solid and liquid ghost temperature values $T_{s, l}^{\prime G}$ can be obtained using the following linear extrapolation (for example, Figure 3(a)):

$$
T_{s, l}^{G}=\left(1-\frac{\phi_{l, s}}{\phi_{s, l}}\right) T_{I}^{\prime}+\frac{\phi_{l, s}}{\phi_{s, l}} T_{s, l}^{\prime}
$$

where $T_{l}^{\prime}$ is the nondimensional solid-liquid interface temperature. The system of algebraic equations resulting from the preceding discretization is tridiagonal and can be easily solved using the Thomas algorithm. ${ }^{[26]}$

At each instant $t_{n}^{\prime}$, the nondimensional velocity $V_{n}^{\prime}$ of the solid-liquid interface is obtained by the Stefan condition:

$$
V_{n}^{\prime}=\frac{d X_{I}^{\prime}}{d t^{\prime}}=-\operatorname{St}\left(\frac{\partial T_{l}^{\prime}}{\partial \mathbf{n}}-\frac{k_{s}}{k_{l}} \frac{\partial T_{s}^{\prime}}{\partial \mathbf{n}}\right)
$$

where $\mathrm{St}$ is the Stefan number given by $\mathrm{St}=$ $\left(T_{m}-T_{0}\right) c_{l} / L$, with $L$ the latent heat of fusion and $\mathbf{n}$ the normal vector to the interface. Similarly, as in 


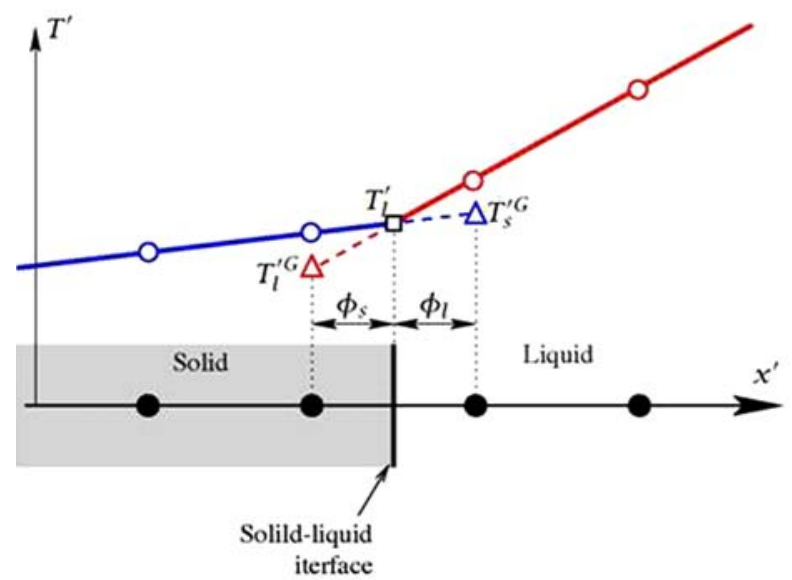

(a)

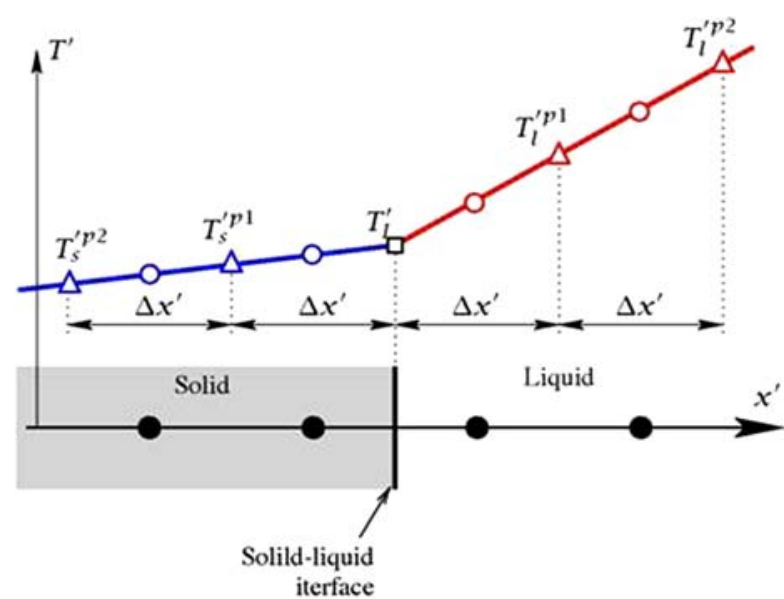

(b)

Fig. 3-Example of $(a)$ ghost temperature values extrapolation and $(b)$ probe temperature values interpolation on both sides of the solid-liquid interface.

Udaykumar et al., ${ }^{[27]}$ for two-dimensional problems, the temperature gradients at each side of the interface are calculated using the following second-order finitedifference approximation:

$$
\frac{\partial T_{s, l}^{\prime}}{\partial \mathbf{n}}=\frac{4 T_{s, l}^{\prime p 1}-T_{s, l}^{\prime p 2}-3 T_{l}^{\prime}}{2 \Delta x^{\prime}}
$$

where $T_{s . l}^{\prime p 1}$ and $T_{s . l}^{\prime p 2}$ are the nondimensional temperature values at the probe nodes located, respectively, at distances $\Delta x^{\prime}$ and $2 \Delta x^{\prime}$ from the solid-liquid interface. These values are obtained by linear interpolation from the temperature distribution on both sides of the interface (example in Figure 3(b)). Once the interface velocity $V_{n}^{\prime}$, is obtained from Eq. [13], the solid-liquid interface $X_{I}^{\prime}$, is explicitly advanced to the next instant $t^{\prime}{ }_{n+1}$.

A uniform grid step size $\Delta x^{\prime}$ was used and the timestep size $\Delta t^{\prime}$ was chosen to satisfy $\Delta t^{\prime}=50 \Delta x^{\prime 2}$ when the particle is completely melted or solidified, or $\Delta t^{\prime}=\min \left(50 \Delta x^{\prime 2}, 0.1 \Delta x^{\prime} / V_{n}^{\prime}\right)$ when the particle is partially solidified.

The values of the thermophysical properties of the particles are shown in Table II (the properties of the surrounding gas are also included in the table). Note that although the properties of the solid and liquid phases are considered identical in this work, different values could be introduced into the model with no loss of generality. The gas temperature and velocity were obtained from the previous solution of the CFD model at a finite number of discrete points along the centerline. During the particle thermal simulations, the temperature and velocity of the gas in other centerline locations may be needed. These values were obtained from a natural cubic spline interpolation based on the mentioned CFD results.

Different grids were used to check the grid dependency of the solution for the cases presented in this work. An increase in the grid size from 81 to 161 nodes along the radial coordinate of the particle produced differences in the numerical results for the mean temperature of less than $0.05 \mathrm{pct}$ in the most unfavorable cases.
We conclude that using 81 nodes along the radial coordinate produced nearly grid-independent results for all the cases presented in this work.

It should be mentioned that in all the cases considered in this work, the Biot number was lower than 0.03 , which means that the thermal gradient inside the particle could be considered negligible and that the governing equations of the heat transfer between a single particle and the gas may be reduced to a firstorder ordinary differential equation. Therefore, simpler thermal models, such as those proposed by Cheng et al. ${ }^{[14]}$ or $\mathrm{Li}$ and Christofides, ${ }^{[20]}$ among others, may produce sufficiently accurate results for spherical particles. However, the idea behind this work was to develop a more general model, albeit at the cost of a more complex implementation, which can be used for other operating conditions and can serve as a framework for future extensions to higher dimensions to accurately study the thermal behavior of particles with any type of nonspherical shape. This will be the subject of a future work.

\section{EXPERIMENTAL METHODOLOGY}

Several Fe-based amorphous metal formulations have been found that appear to be corrosion resistant comparable to, or better than, Ni-based alloy C-22, according to the breakdown potential and corrosion rates. ${ }^{[28]}$ These formulations use chromium $(\mathrm{Cr})$, molybdenum (Mo), and tungsten (W) to provide corrosion resistance; boron (B) to enable glass formation; and yttrium to lower the critical cooling rate (CCR). The Fe-based amorphous alloy used in this work is identified as SAM1651. The alloy has high carbon content $\left(\mathrm{Fe}_{48} \mathrm{Cr}_{15} \mathrm{Mo}_{14} \mathrm{~B}_{6} \mathrm{C}_{15} \mathrm{Y}_{2}\right)$ and a nominal CCR of only $80 \mathrm{~K} / \mathrm{s}$. The low CCR, due to the addition of yttrium, enables it to be rendered as a completely amorphous thermal spray coating. The amorphous powder was sieved and classified into two groups of particle size prior to spray experiments, 16 to $25 \mu \mathrm{m}$ and 25 to $53 \mu \mathrm{m}$ (Figure 4). 
Before spraying, the substrates were degreased, grit blasted, and cleaned with acetone. A Sulzer Metco Diamond Jet DJ 2700 HVOF thermal spray facility (Sulzer Metco Inc., Westbury, NY) was used for thermal spraying of the Fe-based powders. The spraying parameters are summarized in Table I. Values are given in standard cubic feet per hour (SCFH), because this is the practical unit used on the control console of the DJ 2700 system.

X-ray diffraction (XRD) measurements were carried out with a Scintag XDS-2000 diffractometer (Scintag, Cupertino, CA) equipped with a graphite

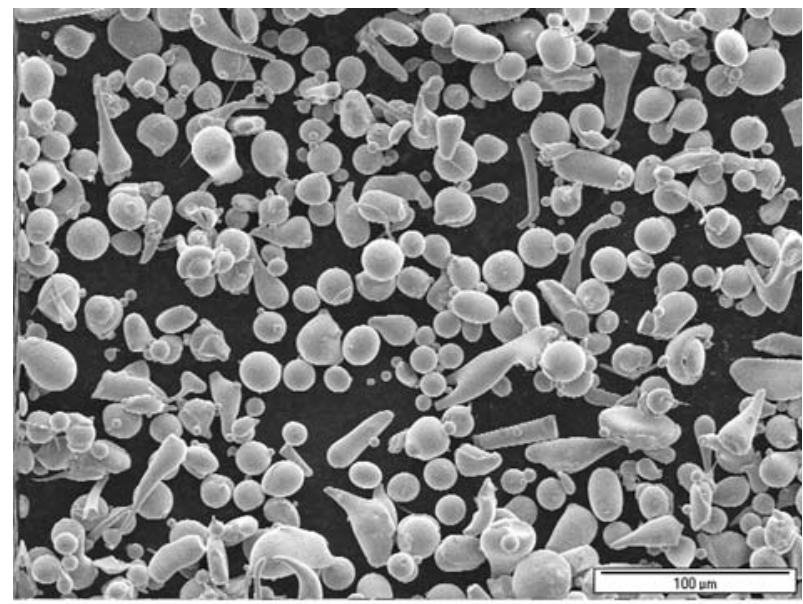

(a)

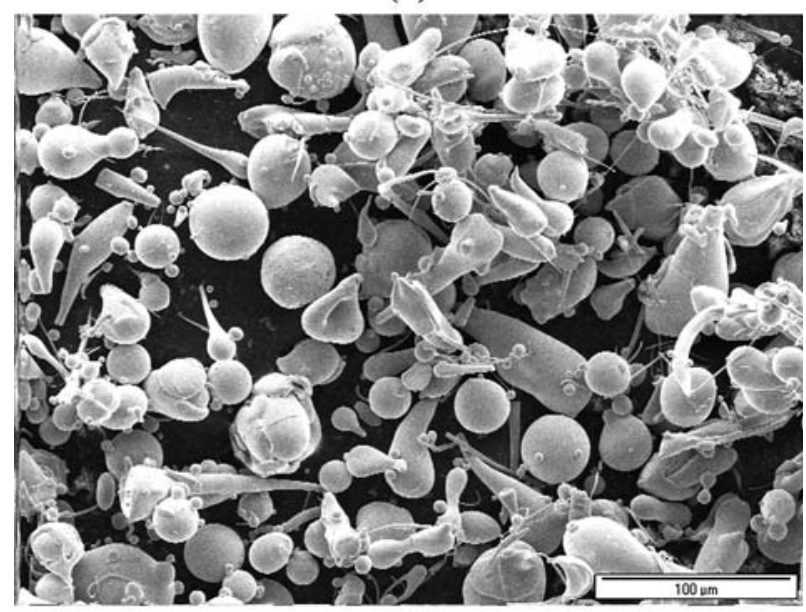

(b)

Fig. 4-Particle morphology of the SAM1651 powder: (a) 16 to $25 \mu \mathrm{m}$ and (b) 25 to $53 \mu \mathrm{m}$. monochromator using $\mathrm{Cu} K_{\alpha}$ radiation. The coatings microstructure was examined using a PHILIPS* XL30

*PHILIPS is a trademark of Philips Electronic Instruments Inc., Mahwah, NJ.

field emission gun scanning electron microscope. Prior to SEM observations, cross sections of the coating were prepared by standard metallographic techniques. Backscattered electron images were obtained, and energy dispersive spectrometry analysis was conducted on the coating samples.

\section{RESULTS AND DISCUSSION}

\section{A. Effects of Gas Flow Rate and Fuel-to-Oxygen Ratio}

In this HVOF gun system, key process variables are total gas flow rate, oxygen-to-fuel mass ratio, and standoff distance between combustion nozzle and substrate. The results presented in this section relate once again to the gun geometry of Figure 1, in which the combustion nozzle length is around $77 \mathrm{~mm}$. The gas flow rates and fuel-to-oxygen ratios correspond to values described in the experimental procedures. The effect of varying the gas flow parameters on flow behavior was examined. Three different propylene mass flow rates were considered, namely, 144, 180, and 216 $\mathrm{SCFH}$, and, for each rate, three fuel-to-oxygen ratios, namely, $0.25,0.31$, and 0.373 , were investigated. The oxygen mass flow rate and air mass flow rate were fixed as 578 and $857 \mathrm{SCFH}$, respectively.

Table II. Values of Material Properties Used in the Numerical Model

Powder Properties Used for Sam1651

Density, $\mathrm{kgm}^{-3}$

Melting temperature, $\mathrm{K}$

Latent heat of fusion, $\mathrm{Jkg}^{-1}$

Specific heat capacity, $\mathrm{Jkg}^{-1} \mathrm{~K}^{-1}$

Thermal conductivity, $\mathrm{Wm}^{-1} \mathrm{~K}^{-1}$

Gas Properties

Density, $\mathrm{kgm}^{-3}$

Specific heat capacity, $\mathrm{Jkg}^{-1} \mathrm{~K}^{-1}$

Thermal conductivity, $\mathrm{Wm}^{-1} \mathrm{~K}^{-1}$

Dynamic viscosity, $\mathrm{kgm}^{-1} \mathrm{~s}^{-1}$

0.35

1250

0.08

$5 \cdot 10^{-5}$

Table I. Inlet Gas Mass Flow Rates and Pressure

\begin{tabular}{|c|c|c|c|c|c|c|}
\hline \multirow[b]{2}{*}{ Case } & \multicolumn{2}{|c|}{ Oxygen } & \multicolumn{2}{|c|}{ Propylene } & \multicolumn{2}{|c|}{ Air } \\
\hline & $\begin{array}{l}\text { Mass Flow } \\
\text { Rate (SCFH) }\end{array}$ & $\begin{array}{l}\text { Pressure } \\
\text { (psi) }\end{array}$ & $\begin{array}{c}\text { Mass Flow } \\
\text { Rate (SCFH) }\end{array}$ & $\begin{array}{l}\text { Pressure } \\
\text { (psi) }\end{array}$ & $\begin{array}{l}\text { Mass Flow } \\
\text { Rate (SCFH) }\end{array}$ & $\begin{array}{c}\text { Pressure } \\
\text { (psi) }\end{array}$ \\
\hline A & 578 & 150 & 144 & 105 & 857 & 100 \\
\hline B & 578 & 150 & 180 & 105 & 857 & 100 \\
\hline $\mathrm{C}$ & 578 & 150 & 216 & 105 & 857 & 100 \\
\hline
\end{tabular}




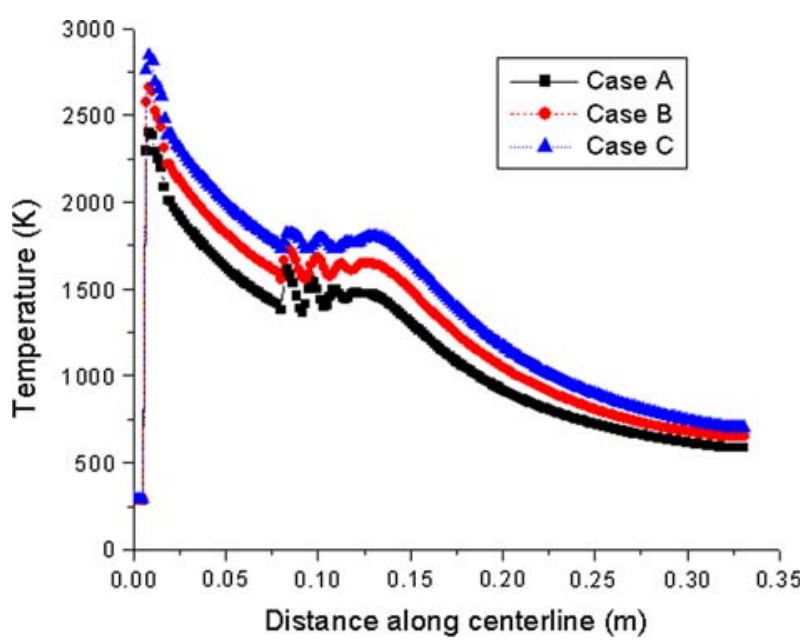

Fig. 5-Temperature distribution along centerline.

Centerline gas temperatures are plotted $v s$ axial distance in Figure 5. This form of presentation is particularly relevant to developing a semiquantitative understanding of how powder particles will be affected by different process variables, since it has already been demonstrated that the carrier gas flow remains closely aligned with the symmetry axis. ${ }^{[13,14]}$ The maximum temperature reached within the combustion nozzle is found to vary with gas flow rate ratio, as shown in Figure 5.

The general trend for the gas temperature is to increase sharply within the combustion nozzle and to reach the peak within the vicinity of nozzle inlet before decreasing along the length of the nozzle. It is noted that the higher centerline temperature is around $2700 \mathrm{~K}$, i.e., right below the highest flame temperature for propylene. Outside the gun, the temperature is only affected by the flow rate. It is apparent that the total gas flow rate and gas flow rate ratio have a negligible effect on the gas temperature distribution trend within the nozzle. However, the higher total flow rate and higher fuel-to-oxygen ratios give a higher centerline temperature.

This form of presentation is particularly relevant to developing a semiquantitative understanding of how powder particles will be affected by different process variables, since it has already been demonstrated that the carrier gas flow remains closely aligned with the symmetry axis. ${ }^{[13,14]}$ The maximum temperature reached within the combustion nozzle is found to vary with the gas flow rate ratio, as shown in Figure 5.

Figure 6 shows the centerline axial gas velocities plotted against axial distance. The overall trend is that the velocity increases sharply in the convergent portion of the nozzle but increases gradually in the divergent region. At the exit of the nozzle, the velocity increases and decreases as a result of expansion-compression wave circles just outside the nozzle and then undergoes a slow decay after four diamond shocks as ambient air reaches the centerline. Both total flow rate and gas ratio affect the velocity profile. Maximum velocity is achieved at the highest total gas mass flow rate and the highest fuelto-oxygen ratio (0.373). Conversely, the lowest gas mass

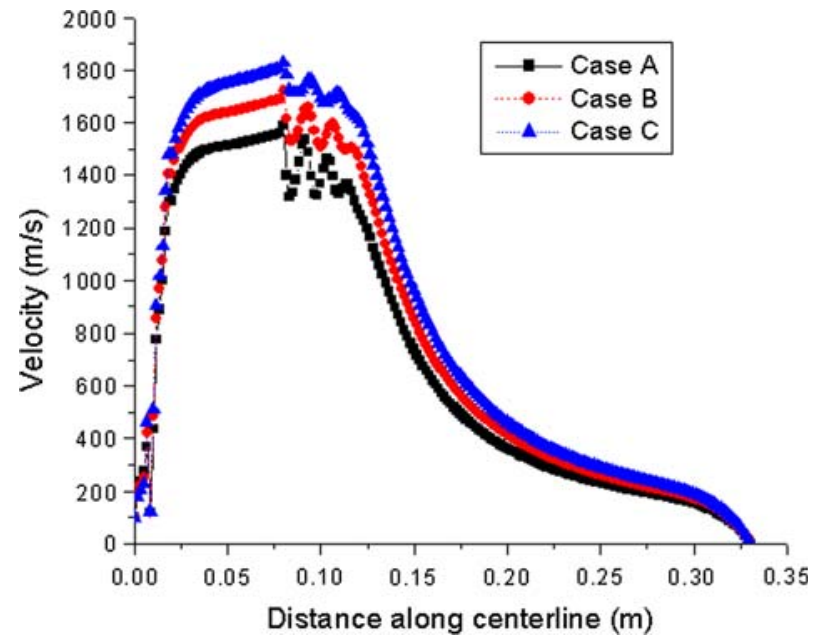

Fig. 6-Velocity distribution along centerline.

flow rate and lowest oxygen-rich ratio $(0.25)$ led to the lowest velocity.

These steady-state flow field calculations demonstrate the potential effect of variations in the process parameters on powder particle heating and oxidation. First, an increase in total gas flow rate will cause powder particles to fly at higher speeds and experience higher gas temperatures. Second, an increase in the fuel-to-oxygen gas ratio at a fixed total flow rate will marginally increase gas velocity with little effect on gas temperature. Meanwhile, it will have a strong effect on the oxygen content of the gas and could reduce the oxidation of sprayed materials.

The general trend for the gas temperature is to increase sharply within the combustion nozzle and to reach the peak within the vicinity of nozzle inlet before decreasing along the length of the nozzle. It is noted that the higher centerline temperature is around $2700 \mathrm{~K}$, i.e., right below the highest flame temperature for propylene. Outside the gun, the temperature is only affected by the flow rate. It is apparent that the total gas flow rate and gas flow rate ratio have a negligible effect on the gas temperature distribution trend within the nozzle. However, the higher the total flow rate and fuelto-oxygen ratios, the higher the centerline temperature.

\section{B. Effects of Flame Conditions on Particle Velocity and Temperature}

Figure 7 represents the mean particle temperature (left column) and particle velocity (right column) as a function of the distance along the centerline for particle diameters ranging between 10 and $60 \mu \mathrm{m}$ and gas flow conditions corresponding to cases $\mathrm{A}, \mathrm{B}$, and $\mathrm{C}$ of Table I. The gas temperature $T_{g}$ and velocity $\mathbf{v}_{g}$ obtained from the previous solution of the CFD model are also included in the figure with dotted lines. It can be observed that the mean temperature and velocity of the particles increase as the particle diameter decreases, for a given gas flow condition, and as the fuel-tooxygen ratio increases, for a given particle diameter. The smallest particles may reach velocities as high as 

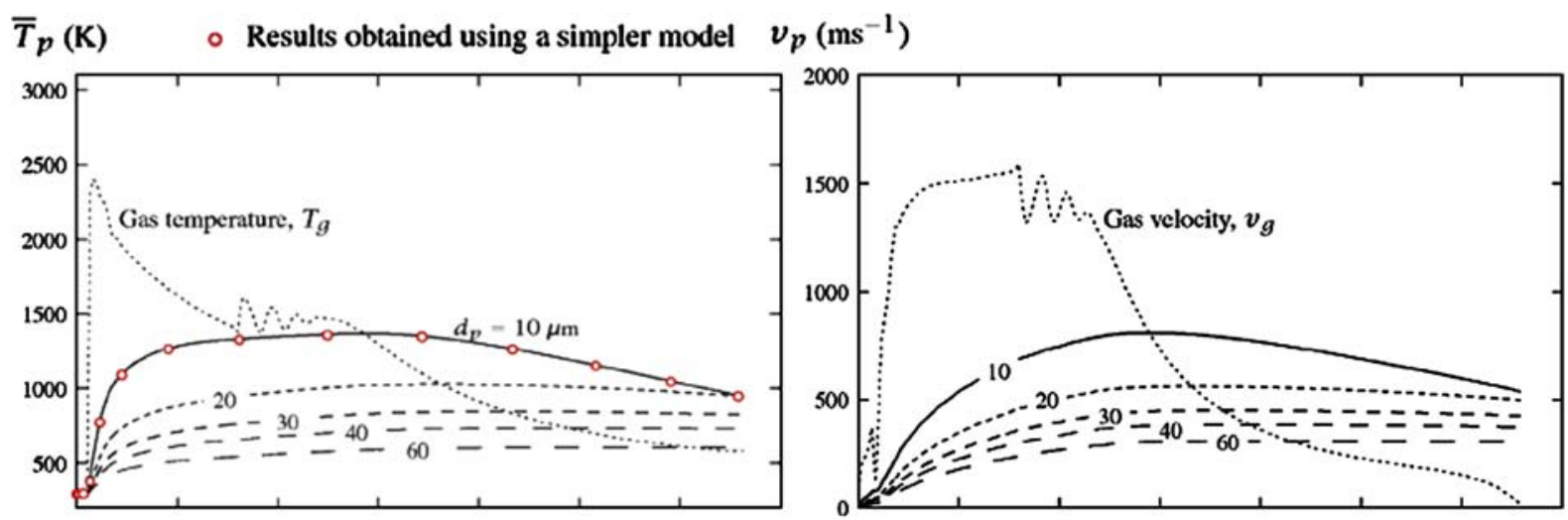

(a)
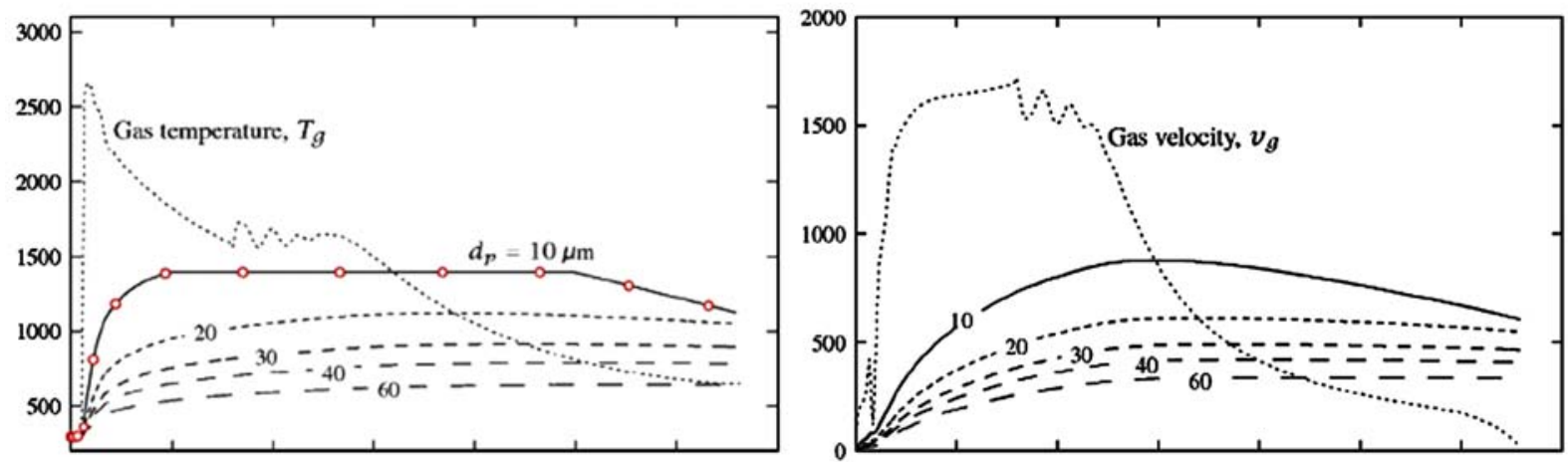

(b)
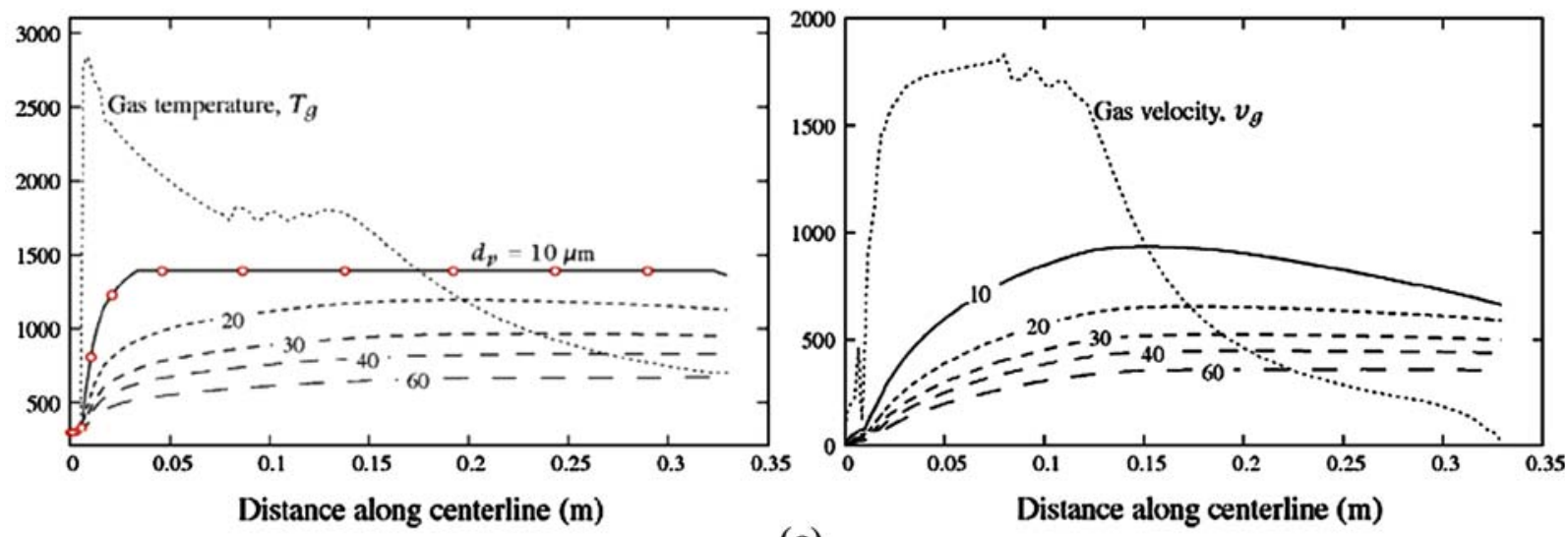

(c)

Fig. 7-Mean particle temperature (left column) and particle velocity (right column) for different particle diameters (ranging between 10 and $60 \mu \mathrm{m}$ ) and gas flow conditions (cases A, B, and C of Table I) as a function of the distance along the centerline. The open circles correspond to the results obtained with a simpler model similar to that used by Cheng et al. ${ }^{[14]}$

$900 \mathrm{~ms}^{-1}$, although they are then sharply decelerated due to their relatively lower momentum inertia. For larger particles, the acceleration is slower and the maximum velocity is reached as they impact on the substrate. On the other hand, it can be seen that only the smaller particles are heated to melting point and that these are only partially melt during flight (in the case of particles with diameter equal to $10 \mu \mathrm{m}, 14$ and 35 pct of the total volume of the particle is melted during in-flight behavior for cases B and C, respectively). Even in that situation, note that the particles will reach the substrate completely solidified due to the high cooling rates (the values of the cooling rate of the smaller particles just before reaching the substrate may be as high as around $1.6 \cdot 10^{6}, 2.1 \cdot 10^{6}$, and $2.9 \cdot 10^{6}$ for the gas flow conditions $\mathrm{A}, \mathrm{B}$, and $\mathrm{C}$, respectively). For larger particles, the temperature, which increases slowly and becomes almost constant near the substrate, does not reach the melting point and the particles will keep their solid state.

The results of a simpler model, similar to that used by Cheng et al. ${ }^{[14]}$ and implemented by us only for validation purpose, are represented with open circles in Figure 7 for the lowest particle diameter and different flow gas conditions. Note that the differences between 
the results of the simpler model and those obtained with the proposed model (continuous line) are very small, which makes the use of simpler models sufficiently accurate for the operating conditions considered in this work. For future works, however, the proposed model will allow us to obtain, in a straightforward manner, accurate results for more general cases, such as those corresponding to operating conditions with higher Biot numbers; large differences between the physical properties of liquid and solid phases; or extremely rapid solidifications, such as those produced during recalescence processes (the last situation would occur for particle diameters smaller than those considered in this work).

\section{Coating Microstructure}

The powder and coating XRD patterns (Figure 8) have shown that there is no crystallization or at least no X-ray detectable crystallization of the powder after gas atomization and on the coatings after HVOF processing.

A typical and representative cross section of the coating is shown in Figure 9 (this particular coating was sprayed using condition B of Table I and 25- to 53- $\mu \mathrm{m}$ powder size distribution). All the deposited coatings studied in this work showed limited porosity $(<1 \mathrm{pct})$. Figure 10 shows BSE images of the coatings produced from the 16 - to $25-\mu \mathrm{m}$ powder in the three spray conditions A, B, and C described in Table I. Dark areas in the images correspond to oxidized regions of the coating. It is noticeable that sample $\mathrm{C}$ presented slightly more oxidized regions than A and B. Energy dispersive spectrometry analysis on the oxide regions has shown the presence of $\mathrm{Fe}$ and small traces of $\mathrm{Y}$ element, suggesting that those regions are likely to be composed of Fe oxides with a smaller amount of yttrium oxide.

According to the results presented in Figure 7, particles sprayed in conditions $\mathrm{C}$ experienced higher temperatures and velocities than those sprayed in

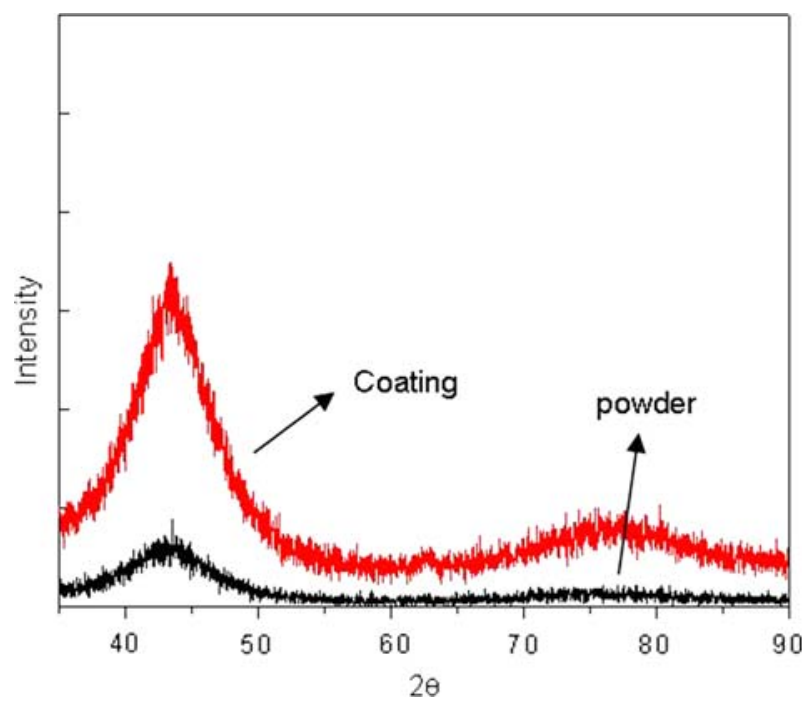

Fig. 8-XRD patterns of the SAM1651 powder and HVOF coating (sprayed with conditions B of Table I and powder size from 25 to $53 \mu \mathrm{m})$. conditions A and B. The microstructure observed in Figure 10 corroborates the numerical results, as sample $\mathrm{C}$ presented higher oxide content than $\mathrm{A}$ and $\mathrm{B}$, suggesting higher temperatures during spraying.

The coating microstructure results also suggest that the small particles probably experienced melting, extensive deformation, and severe oxidation, as predicted by the numerical modeling. On the other hand, larger $(>16 \mu \mathrm{m})$ particles do not reach the melting point but also undergo extensive flattening and plastic deformation during impact. This extensive deformation of the large particles is well documented in Figure 11, where the cross section of the coating produced with the 25- to $53-\mu \mathrm{m}$ powder is presented. Two important observations can be drawn from this image: first, the coating presented significantly less oxidation, suggesting much lower in-flight temperatures as predicted by the model; and second, even large particles $(53 \mu \mathrm{m})$ underwent extensive deformation and flattening, since no "undeformed" particles could be found in the coating cross section. This result suggests that the material as a metallic glass could reach its glass transition temperature during spraying and easily deform to fill in all the gaps in the coating; it also explains its low porosity without the need to achieve melting.

The yttrium-containing SAM1651 formulation has a glass transition temperature of $\sim 584{ }^{\circ} \mathrm{C}$, a crystallization temperature of $\sim 653{ }^{\circ} \mathrm{C}$, and a melting point of $\sim 1121{ }^{\circ} \mathrm{C}$. Because crystallization or devitrification was not observed or detectable from the SEM and XRD results in any of the coatings, one can speculate that the crystallization temperature was never reached for the unmelted large particles, as indicated by the numerical results. It is possible, however, that these particles could experience melting and fast cooling rates upon impact that prevented crystallization, which would contradict our numerical results. Moreover, the small melted particles may cool at a rate as high as $10^{4} \mathrm{~K} / \mathrm{s}$ during splatting and solidification upon impact. Given the low CCR of the SAM1651 alloy $(85 \mathrm{~K} / \mathrm{s})$, formation of an amorphous glass is certain to occur.

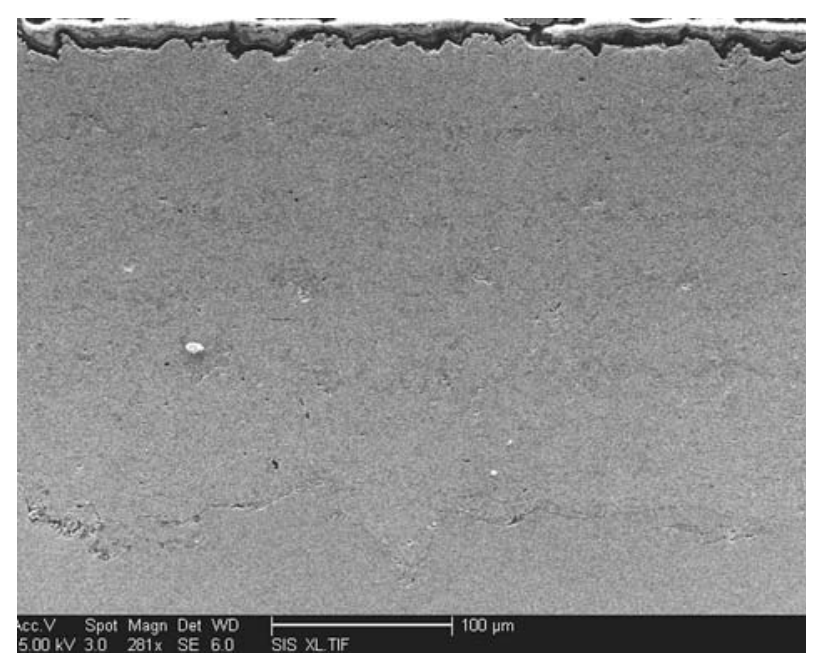

Fig. 9-Typical microstructure of the SAM1651 coatings. 


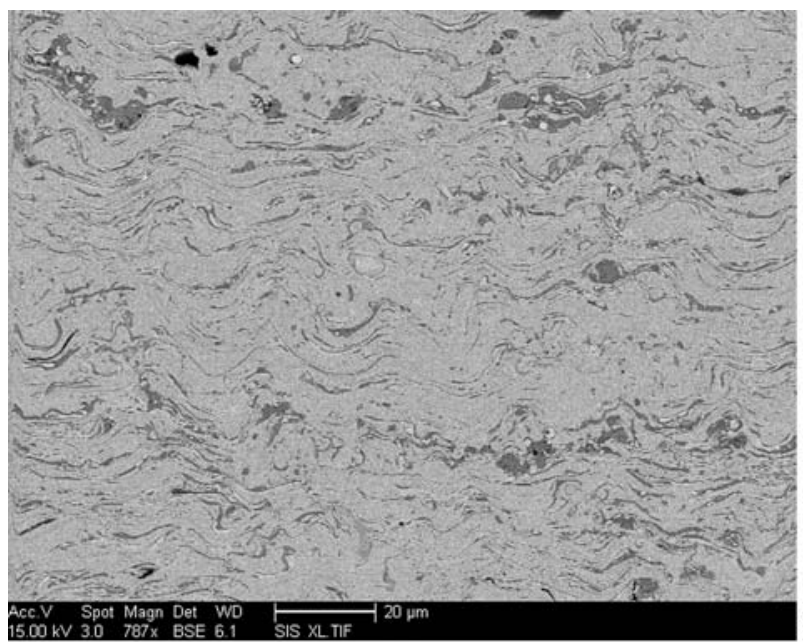

(a)

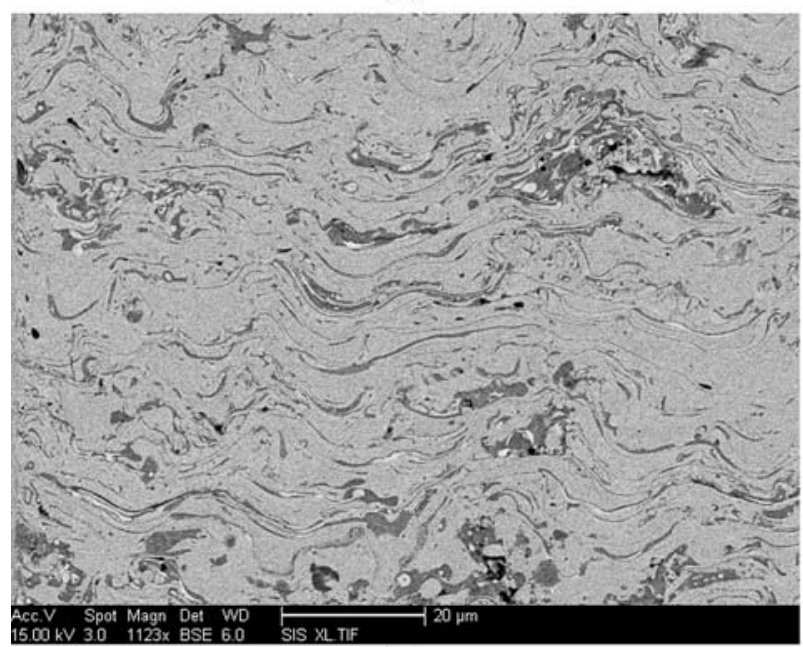

(c)

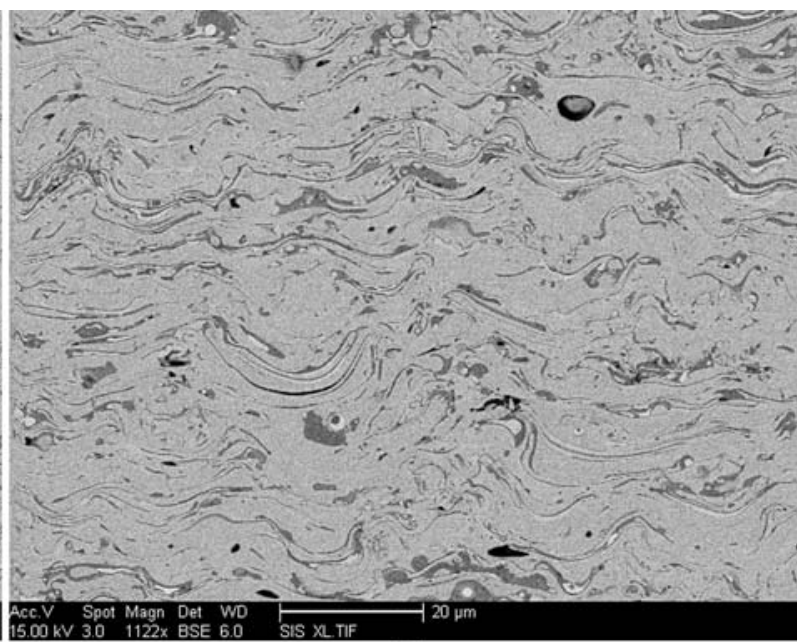

(b)

Fig. 10-BSE images of the coatings produced from the 16- to $25-\mu \mathrm{m}$ powder size at the three spray conditions A, B, and C described in Table I, respectively.

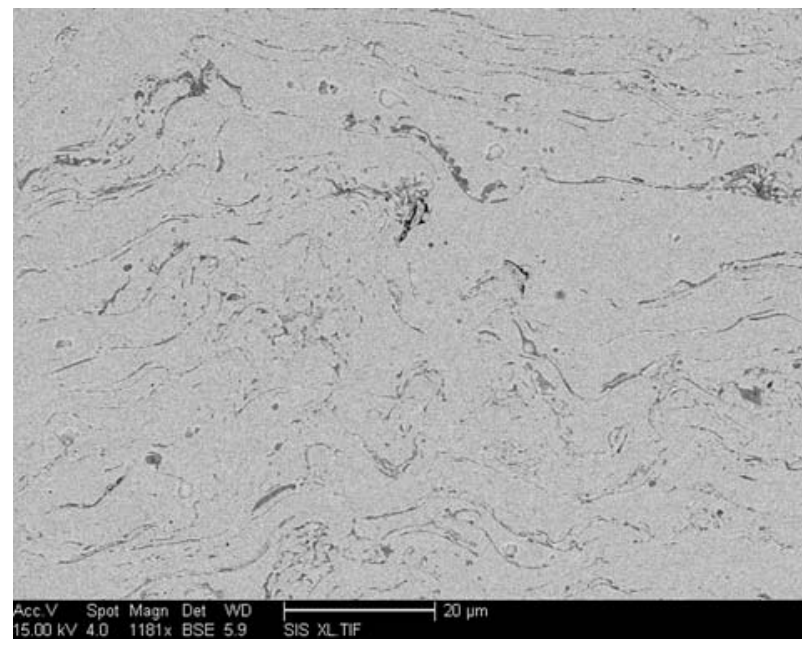

Fig. 11-BSE images of the coating produced from the $25-$ to $53-\mu \mathrm{m}$ powder at the spray conditions B described in Table I.

\section{CONCLUSIONS}

A comprehensive CFD model based on CFD-ACE has been applied to investigate the gas flow behavior in a specific HVOF thermal spray system. The model was used to investigate the influence of three different fuelto-oxygen mass ratios on gas temperature and velocity distributions and their effect on particle temperatures and velocities of Fe-based amorphous glass during spraying. The thermal behavior of the particles was analyzed using a one-dimensional decoupled model, which uses an explicit front-tracking method to calculate the solid-liquid interface position at each time-step. Numerical results obtained with the particle thermal model were compared with those obtained with a simpler model, with a good degree of agreement for the operating conditions considered in this work. When the influence of the gas flow conditions on the particle thermal behavior was determined for different particle diameters, the results allowed us to relate the different 
operating conditions with the coating microstructures obtained in this work.

High-quality HVOF coatings were achieved in the spray conditions used in this work, amorphous coatings with less than 1 pct porosity being produced. Different degrees of oxidation were observed depending on particle size and spray conditions. These results can be explained by the temperature distribution predicted by the numerical model. No signs of detectable (by XRD or SEM) crystallization (for the melted material) or devitrification (unmelted material) were observed in the sprayed coatings.

\section{ACKNOWLEDGMENTS}

This work is supported by the Lawrence Livermore National Laboratory under Contract No. B558563. One of the authors (JL) also gratefully acknowledges the support of the Spanish Ministerio de Educación y Ciencia under Grant No. PR2005-0296.

\section{OPEN ACCESS}

This article is distributed under the terms of the Creative Commons Attribution Noncommercial License which permits any noncommercial use, distribution, and reproduction in any medium, provided the original author(s) and source are credited.

\section{REFERENCES}

1. V.V. Sobolev, J.M. Guilemany, and J. Nutting: High Velocity Oxy-Fuel Spraying, Maney Publishing, Leeds, UK, 2004, pp. $233-352$.

2. E.J. Lavernia and Y. Wu: Spray Atomization and Deposition, John Wiley \& Sons, New York, NY, 1997, pp. 7-17.

3. D.W. Parker and G.L. Kutner: Adv. Mater. Process., 1991, vol. 140 , pp. $68-74$.

4. W.L. Johnson: Mater. Sci. Forum, 1996, vols. 225-227, pp. 35-50.
5. R. Busch, Y.J. Kim, and W.L. John: J. Appl. Phys., 1995, vol. 77, p. 4039.

6. A. Peker and W.L. Johnson: Appl. Phys. Lett., 1993, vol. 63, pp. 2342-44.

7. A. Inoue: Mater. Trans. JIM, 1995, vol. 36, pp. 866-75.

8. A. Inoue, T. Zhang, and T. Masumoto: Mater. Trans. JIM, 1989, vol. 30 , pp. $965-72$.

9. A. Inoue, T. Zhang, and T. Masumoto: J. Non-Cryst. Solids, 1993, vols. $156-158$, pp. $473-80$.

10. W.H. Wang, Z.X. Bao, C.X. Liu, D.Q. Zhao, and J. Eckert: Phys. Rev. B, 2000, vol. 61, pp. 3166-69.

11. W.H. Wang, Q. Wei, S. Friedrich, M.P. Macht, N. Wanderka, and H. Wollenberger: Appl. Phys. Lett., 1997, vol. 71, pp. 1053-55.

12. D.J. Branagan, W.D. Swank, D.C. Haggard, and J.R. Fincke: Metall. Mater. Trans. A, 2001, vol. 32A, pp. 2615-21.

13. D. Cheng, Q. Xu, G. Trapaga, and E.J. Lavernia: Metall. Mater. Trans. A, 2001, vol. 32A, pp. 1609-20.

14. D. Cheng, Q. Xu, G. Trapaga, and E.J. Lavernia: Metall. Mater. Trans. B, 2001, vol. 32B, pp. 525-35.

15. S. Gu, C.N. Eastwick, K.A. Simmons, and D.G. McCartney: J. Thermal Spray Technol., 2001, vol. 10, pp. 461-69.

16. W.L. Oberkampf and M. Talpallikar: Proc. 7th Nat. Thermal Spray Conf., Boston, MA, 1994, pp. 381-92.

17. B. Hassan, A.R. Lopez, and W.L. Oberkampf: J. Thermal Spray Technol., 1998, vol. 7, pp. 71-77.

18. C.H. Chang and R.L. Moore: J. Thermal Spray Technol., 1995, vol. 4, pp. 358-66.

19. V.V. Sobolev, J.M. Guilemany, A.J. Martin, J.A. Calero, and P. Vilarrubias: J. Mater. Process. Technol., 1998, vol. 79, pp. 21316.

20. M. Li and P.D. Christofides: Chem. Eng. Sci., 2005, vol. 60, pp. 3649-69.

21. M. Li, D. Shi, and P.D. Christofides: Powder Technol., 2005, vol. 156, pp. 177-94.

22. F.M. White: Fluid Mechanics, McGraw-Hill, New York, NY, 2002, pp. 135-224.

23. W.E. Ranz and W.R. Marshall: Chem. Eng. Prog., 1952, vol. 48, pp. 141-46.

24. L. Pawlowski: The Science and Engineering of Thermal Spray Coatings, 2nd ed., Wiley, Chichester, England, 2008, pp. 167-214.

25. W.H. Press, S.A. Teukolsky, W.T. Vetterling, and B.P. Flannery: Numerical Recipes in Fortran, 2nd ed., Cambridge University Press, Cambridge, United Kingdom, 1992, pp. 704-07.

26. L.H. Thomas: Watson Science Computer Laboratory Report, Columbia University, New York, NY, 1949.

27. H.S. Udaykumar, R. Mittal, and W. Shyy: J. Comput. Phys., 1999, vol. 153 , pp. $535-74$.

28. R.B. Rebak, S. Daniel Day, T. Lian, P.D. Hailey, and J.C. Farmer: Metall. Mater. Trans. A: Phys. Metall. Mater. Sci., 2008, vol. 39 (2), pp. 225-34. 